\title{
Variation in soil water content to rainfall under Caragana microphylla shrub in Horqin Sandy Land
}

\author{
ShaoKun WANG ${ }^{1,2^{*}}$, XueYong ZHAO ${ }^{1}$, Hao QU ${ }^{1,2}$, YaYong LUO ${ }^{1,2}$, JianYing YUN ${ }^{1}$ \\ ${ }^{1}$ Naiman Desertification Research Station, Cold and Arid Regions Environmental and Engineering Research Institute, Chinese \\ Academy of Sciences, Lanzhou 730000, China; \\ ${ }^{2}$ Graduate University of Chinese Academy of Sciences, Beijing 100039, China
}

\begin{abstract}
In order to investigate the spatio-temporal variability of soil water content to rainfall under Caragana microphylla shrub in Horqin Sandy Land, a plot of $25 \mathrm{~m} \times 25 \mathrm{~m}$, where there were 6 shrub canopies of $C$. microphylla, was sited for measuring soil water content at two soil layers of $0-20 \mathrm{~cm}$ (top layer) and 20-40 cm (lower layer). Soil water content was measured on the 1st, 5th, 10th and 15th day after a $42 \mathrm{~mm}$ rainfall in Naiman of Inner Mongolia. The results showed that soil water contents at both layers under $C$. microphylla shrub were gradually decreased after the rain. Soil water content at the top layer outside the shrub canopy was higher than that inside the shrub canopy within 5 days, and became similar inside and outside the shrub canopy on the 10th day after the $42 \mathrm{~mm}$ rainfall, and it was lower outside than that inside the shrub canopy on the 15th day. The soil water content at lower layer in the area without shrubs was higher than that under shrub canopy all along. All the measured values of soil water content can be fitted to a variogram model. There was significant autocorrelation of the values of soil water content between top layer and lower layer, except for the fourth measured values of soil water content at top layer. The range and spatial dependence of soil water content at top layer were lower than that at lower layer.
\end{abstract}

Keywords: Horqin Sandy Land; Caragana microphylla; soil water content; spatial variability

\section{Introduction}

Soil water content (SWC) is a very important factor in sandy land ecosystem, and it determines soil formation, development and productivity, and it also controls the formation and development of plantation in sandy land (Sharma, 1991; Liu et al., 1997). The spatial and temporal variation of soil water content is an important subject in sandy land researches (Wang et al., 2006; Zhao et al., 2006). A lot of researches have focused on the characteristic and dynamic of soil water content and the response of soil water content under different land use and plantation in sandy land (Zhao et al., 2002; Chen et al., 2003; He et al., 2003, Zhao et al., 2006; Kang et al., 2007; Huang et al., 2008), and few on the response of soil water content to rainfall under shrubs in arid and semi-arid area (Zhao et al., 1992; Zuo et al., 2005; Hu et al., 2006).

Horqin Sandy Land is located in the semi-arid area of southeast Inner Mongolia, China. The primary landscape was tree-scattered grassland. After decades of exploration, such as extensive fuelwood gathering, overgrazing, and heavy reclamation, the environment had been destroyed. This area has become one of the most severely desertified regions in northern China (Zhu and Chen, 1994; Zhao et al., 2005).

Caragana microphylla $\mathrm{L}$. is a leguminous plant and one of the most common shrubs in Horqin Sandy Land. The plant can resist cold and drought, and survive in sandy and infertile soil. So it is popularly selected to setup shelter-belts to reduce wind erosion and protect the environment in Horqin Sandy Land (Alamusa et al., 2002; Shi et al., 2006).

Study on the spatial and temporal variability of soil water content in sandy land under shrubs is very important for the control of desertification, the restoration of degraded ecosystem, and the exploration and development in sandy land. This paper aims to study the spatial and temporal variability of soil water content under $C$. microphylla shrub to rainfall by using

Received 2010-04-07, accepted 2010-05-18

doi: 10.3724/SP.J.1227.2010.00174

*Corresponding author: ShaoKun Wang (E-mail: wangsk@1zb.ac.cn) 
geostatistical analysis and provides theoretical supports for desertification reversion with bushes.

\section{Study area and methods}

\subsection{Study area}

This study was conducted in the southwestern Horqin Sandy Land, Inner Mongolia, China $\left(42^{\circ} 41^{\prime} \mathrm{N}\right.$, $120^{\circ} 55^{\prime} \mathrm{E}, 360 \mathrm{~m}$ above sea level). The area has a temperate, semiarid continental monsoonal climate and an average annual precipitation of $366 \mathrm{~mm}$, with most of its rainfall in the growing season from June to August. The average annual open-pan evaporation is about $1,935 \mathrm{~mm}$. The annual mean temperature is around $6.4^{\circ} \mathrm{C}$. The annual mean wind velocity is in the range of $3.2 \mathrm{~m} / \mathrm{s}$ to $4.1 \mathrm{~m} / \mathrm{s}$, and the prevailing wind is northwest in winter and spring and southwest in summer and autumn (Zhu and Chen, 1994; Zuo et al., 2009). The zonal soil is sandy chestnut, which is sandy in texture, light yellow in color and loose in structure, and is vulnerable to wind erosion ( $\mathrm{Su}$ et al., 2006; Zhao, 2007).

The restored dunes are covered by weed communities, generally dominated by native plants, including grasses (Setaria viridis L., Euphorbia humifusa L., Bassia dasyphylla L., Ixeris denticulata L., Eragrostis pilosa L., Cleistogenes squarrosa L., Cynanchum thesioides L., Corispermum elongatum L.), shrubs (Caragana microphylla L., Lespedeza dahurica L.) and sub-shrubs (Artemisia frigida L., Artemisia halodendron $\mathrm{L}$.).

\subsection{Experiment design}

The research was carried out in August 2006. In this research, one flat site of fixed sandy land in restoration was selected, southwest to Naiman Desertification Research Station, CAS. The dominant species at this site was Caragana microphylla L., with the coverage of $40 \%-50 \%$. The coverage of other plants, such as Artemisia halodendron L., Setaria viridis L., Corispermum elongatum L., Cynanchum thesioides L., and Euphorbia humifusa L., is less than $20 \%$. In this site, a plot of $25 \mathrm{~m} \times 25 \mathrm{~m}$, with 6 similar and well-growing $C$. microphylla (The length and the width of the 6 canopies were $2.1 \mathrm{~m}$ and $1.5 \mathrm{~m}, 1.9 \mathrm{~m}$ and $1.5 \mathrm{~m}, 1.9 \mathrm{~m}$ and $1.5 \mathrm{~m}, 1.6 \mathrm{~m}$ and $1.6 \mathrm{~m}, 1.8 \mathrm{~m}$ and $1.6 \mathrm{~m}$, and $1.6 \mathrm{~m}$ and $1.5 \mathrm{~m}$, respectively) was chosen to conduct this experiment. We examined the soil water content on the 1 st, 5 th, 10 th and 15 th day after a $42 \mathrm{~mm}$ rain on August 7, 2006. There was no rain during the period of measuring. In this $25 \mathrm{~m} \times 25$ $\mathrm{m}$ plot, 4 transects (northwest/NW, southwest/SW, southeast/SE and northeast/NE) were set for each shrub. Along each direction, 5 spots, which were 0.1 $\mathrm{m}, 0.5 \mathrm{~m}, 1 \mathrm{~m}, 2 \mathrm{~m}$ and $5 \mathrm{~m}$ from the center of $C$. $m i-$ crophylla, were arranged to get soil cores. Shrubs and the core spots were illustrated in Fig. 1. The cores were taken at both $0-20 \mathrm{~cm}$ (top layer) and $20-40 \mathrm{~cm}$ (lower layer) by a soil auger of $20 \mathrm{~mm}$ diameter. Soil water content was determined under $105^{\circ} \mathrm{C}$ for $24 \mathrm{~h}$.

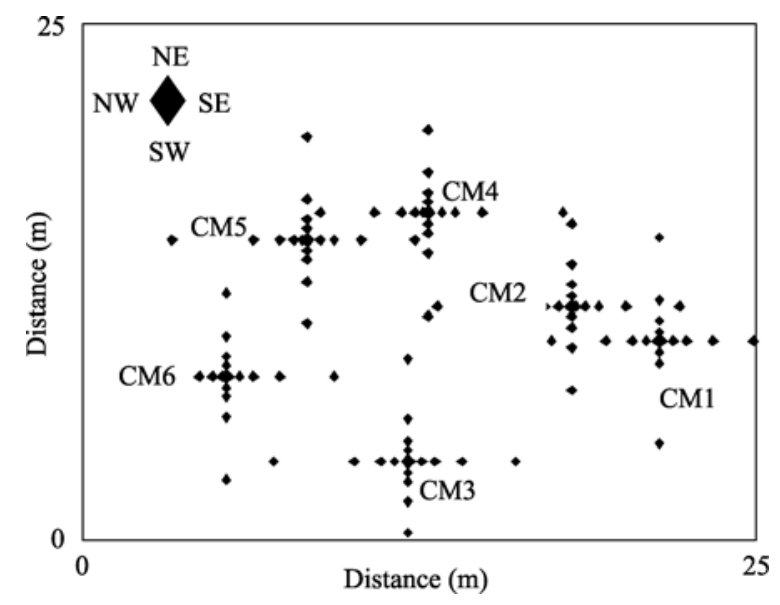

Fig. 1 Site and spots distribution

\subsection{Data analysis}

Data analyses were performed by Microsoft Excel and Origin 8.0 software. The analysis of spatial variation for soil water content was processed using $\mathrm{GS}^{5+}$. Spatial autocorrelation analysis provides a quantitative estimate of spatial correlation between the two kinds of samples (Isaaks and Srivastava, 1989; Zuo et al., 2008). This spatial analysis was implemented by the following formula:

$$
\gamma(h)=\frac{1}{2 N(h)} \sum_{i=1}^{N(h)}\left[z\left(x_{i}\right)-z\left(x_{i}+h\right)\right]^{2} .
$$

Where $\gamma(h)$ is the semivariance at a given distance $h$; $N(h)$ is the number of sample pairs at each distance interval $h ; z\left(x_{i}\right)$ and $z\left(x_{i}+h\right)$ are values of variable at any two places separated by a lag distance $h$. The lag $h$ is defined as a vector with both distance and direction. The spatial structure of the data is determined by fitting a mathematical model to the experimental semivariogram. The model is fitted by means of a least 
squares method. The parameters of the modeled variogram include information on: (1) effective range (A), the separation distance at which spatial dependence is apparent; (2) nugget value $\left(C_{0}\right)$, the level of random variation within the data; (3) structural component $(C)$, the level of structure variation within the data; (4) sill $\left(C_{0}+C\right)$, the total variation present; (5) an especially important parameter, relative structural variance, was calculated as $C /\left(C_{0}+C\right)$. Residual sums of squares (RSS) provided an exact measure of how well the model fit the variogram data, with lower RSS indicating better model fits.

\section{Results and discussion}

\subsection{Temporal variation of soil water content after rain}

SWC at both layers decreased after the $42 \mathrm{~mm}$ rainfall. However, SWC at the lower layers were respectively $31.7 \%, 12.6 \%, 16.3 \%$ and $15.5 \%$ which is higher than that at the top layer on the 1st, 5th, 10th and 15th day. The values were fit to a normal model. Standard deviation (SD) of soil water content reduced as time going on at both layers and the values of coefficient variation $(\mathrm{CV})$ were $19.10 \%, 19.28 \%, 13.71 \%$ and $10.00 \%$ at the top layer and $20.39 \%, 12.81 \%, 14.73 \%$ and $17.60 \%$ at lower layer for the four sampling times, respectively (Table 1 ).

There was no additional rain after the $42 \mathrm{~mm}$ rainfall during the period of the research. SWC diminished as time going on, due to evaporation of top soil and transpiration of vegetation. On the 1st day, SWC at the lower layer was higher than that at the top layer, which is mainly because the soil structure was different at the two layers, and the rain was so heavy that SWC reached its peak at the lower layer after one day's infiltration. This result was consistent with Alamusa et al. (2004), which indicated that the peak of soil water content appeared at $50 \mathrm{~cm}$ soil layer under C. microphylla shrub on the 1st day after rain, but different from the results of Zuo et al. (2005), which showed that soil water content at top layer was higher than that at lower layer on the 3rd day after a $27 \mathrm{~mm}$ rainfall. Zhao et al. (2008) studied SWC variation of Artemisia halodendron, which is also a typical shrub in Horqin Sandy Land, and indicated that SWC decreased by $50 \%$ and $70 \%$ on the 2 nd and 5 th days after a $12.9 \mathrm{~mm}$ rainfall, while in our research SWC decreased by $20 \%$ on the 5 th day after a $42 \mathrm{~mm}$ rainfall.

\subsection{Spatial variation of soil water content after rain}

Within 5 days after the rain it showed that SWC at both layers was getting higher from the centre of the shrubs to $5 \mathrm{~m}$ away from the centre. On the 10th day, SWC at the lower layer outside the shrub canopy was higher than that inside while it was nearly the same at the top layer. On the 15th day, the opposite trend of SWC occurred, and SWC gradually decreased from inside the shrub canopy to outside. The trend at the lower layer outside the shrub canopy was more obvious than that inside, but the range was smaller than that before the 15th day (Fig. 2).

C. microphylla could prevent the rain from infiltration to some extend, and make the rain redistributed. Because there was plenty of soil crust and litter under the shrub canopy, the rain inside the shrub canopy infiltrated slower than that outside, and the water inside

Table 1 Statistical characteristics of soil water content after a $42 \mathrm{~mm}$ rainfall

\begin{tabular}{cccccccc}
\hline Sampling time & Soil layer $(\mathrm{cm})$ & Mean $(\%)$ & SD & Maximum $(\%)$ & Minimum $(\%)$ & CV (\%) & Distribution model \\
\hline \multirow{2}{*}{ 1st day } & $0-20$ & $3.530^{\mathrm{aA}}$ & 0.674 & 4.613 & 2.264 & 19.10 & normal \\
& $20-40$ & $4.649^{\mathrm{aB}}$ & 0.948 & 6.295 & 3.048 & 20.39 & normal \\
\multirow{3}{*}{ 5th day } & $0-20$ & $2.781^{\mathrm{bA}}$ & 0.536 & 3.905 & 1.932 & 19.28 & normal \\
& $20-40$ & $3.131^{\mathrm{bB}}$ & 0.401 & 3.944 & 2.508 & 12.81 & normal \\
\multirow{3}{*}{ 10th day } & $0-20$ & $1.750^{\mathrm{cA}}$ & 0.240 & 2.148 & 1.350 & 13.71 & normal \\
& $20-40$ & $2.036^{\mathrm{CB}}$ & 0.300 & 2.701 & 1.598 & 14.73 & normal \\
15th day & $0-20$ & $1.313^{\mathrm{dA}}$ & 0.131 & 1.592 & 1.087 & 10.00 & normal \\
& $20-40$ & $1.517^{\mathrm{dA}}$ & 0.267 & 2.064 & 1.088 & 17.60 & normal \\
\hline
\end{tabular}

Note: the data were averaged by soil water content of all cores in the 4 directions under 6 shrubs of Caragana microphylla. Values with different lowercase letters are significantly different between the sampling times, and with different uppercase letters represents significant difference between the two layers at $P<$ 0.01 . 

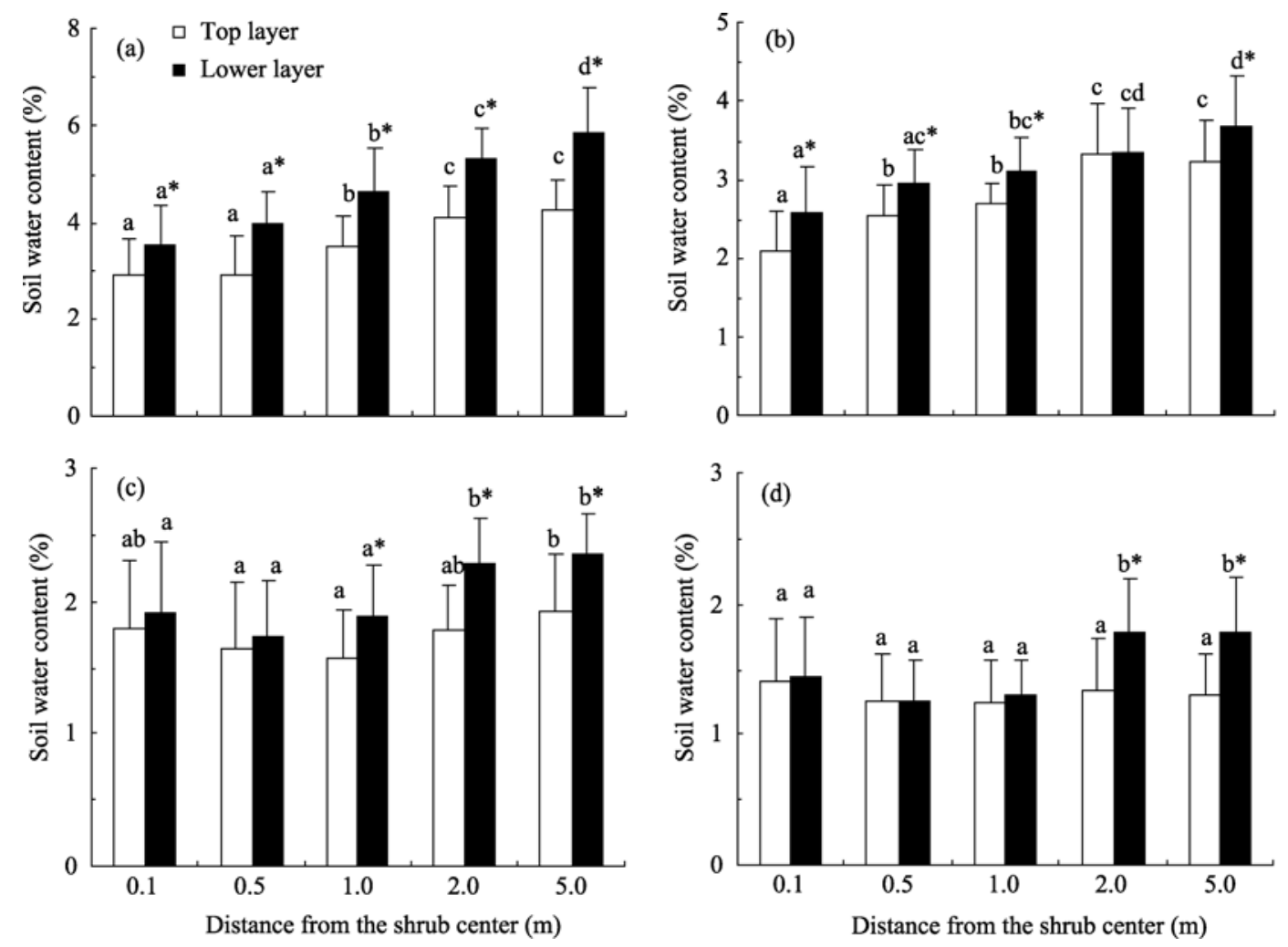

Fig. 2 Spatial variation of soil water content under Caragana microphylla shrub after a $42 \mathrm{~mm}$ rainfall on the 1st day (a), 5th day (b), 10th (c) and 15th day (d). Values (mean \pm SD) with different letters are significantly different between different distances from the center of the shrub, and * represents significant difference between the two layers at $P<0.05$.

diffused to outside. So it showed that SWC outside the shrub canopy was much higher than that inside.

As the evaporation going on, the soil water at the top layer outside the shrub canopy lost faster than that inside because of the protection of shrubs. When drought continued, the transpiration caused the soil water near the shrub lose faster than that away from the plant. It indicated that $C$. microphylla could hold water and make it effective use in sandy land. A similar study on $A$. halodendron revealed that soil water content inside the shrub canopy was lower than that outside within 2 days after a rain, and became similar inside and outside shrub canopy on the 5th day after the rain, while the present research got an equilibrium on the 10th day after the rain because the rain was heavy in our research, and it took time to balance the difference between inside and outside shrub canopy.

\subsection{Semivariance properties of soil water content under Caragana microphylla shrub}

Spatial variance of SWC could fit the theoretical variogram model perfectly at both top and lower lay- ers on the 1st, 5th, 10th and 15th day after the rain. SWC variogram at the top layer on the 1 st and 5 th day, and the lower layer on the 15th day showed spherical model, while the left is fitted exponential model, except that the top layer on the 15th day behaved in linear model. The parameters of the model variogram-based geostatistical analysis for soil water content were summarized in Table 2. According to Jia et al. (2004), a proportion of relative structural variance $C /\left(C_{0}+C\right)$ over $75 \%$ indicates strong spatial autocorrelation, and $75 \%-25 \%$ means moderate autocorrelation, and less than $25 \%$ states low autocorrelation. The values of relative structural variance $C /\left(C_{0}+C\right)$ of SWC at the top layer were $0.953,0.966$, $0.083,0$ and that at the lower layer were $0.860,0.725$, $0.854,0.910$ for the four sampling times, respectively. The results showed SWC represented strong spatial autocorrelation at both layers for the four sampling times, except for the moderate autocorrelation at the lower layer on the 5 th day after the rain. It showed a linear model and the value of $C /\left(C_{0}+C\right)$ equals to 0 at the top layer on the 15th day, indicated that SWC had 
Table 2 Spatial variogram models and parameters of soil water content under Caragana microphylla shrub

\begin{tabular}{|c|c|c|c|c|c|c|c|}
\hline Sampling time & Soil layer $(\mathrm{cm})$ & Model & $C_{0}$ & $C_{0}+C$ & $C /\left(C_{0}+C\right)$ & $\mathrm{A}(\mathrm{m})$ & RSS \\
\hline \multirow{2}{*}{ 1st day } & $0-20$ & Spherical & 0.037 & 0.788 & 0.953 & 1.32 & 0.132 \\
\hline & $20-40$ & Exponential & 0.226 & 1.620 & 0.860 & 2.13 & 0.387 \\
\hline \multirow{2}{*}{ 5th day } & $0-20$ & Spherical & 0.003 & 0.076 & 0.966 & 1.87 & 0.003 \\
\hline & $20-40$ & Exponential & 0.245 & 0.892 & 0.725 & 76.86 & 0.058 \\
\hline \multirow{2}{*}{ 10th day } & $0-20$ & Exponential & 0.023 & 0.200 & 0.883 & 0.06 & 0.002 \\
\hline & $20-40$ & Exponential & 0.005 & 0.034 & 0.854 & 1.83 & 0.000 \\
\hline \multirow{2}{*}{15 th day } & $0-20$ & Linear & 0.138 & 0.138 & 0.000 & - & 0.000 \\
\hline & $20-40$ & Spherical & 0.019 & 0.207 & 0.910 & 2.33 & 0.002 \\
\hline
\end{tabular}

Note: A indicates range, and RSS indicates residual sums of squares.

no spatial autocorrelation under the 15 day's sustained drought in this study, and their spatial autocorrelation may exist in a larger scale.

Effective range (A) indicates the range of spatial autocorrelation of soil water content. There is spatial autocorrelation if the distance is shorter than the value of range, vice versa. The spatial autocorrelation ranges of SWC at the top layer were 1.32, 1.87, and $0.06 \mathrm{~m}$, and they reached to $2.13,76.86,1.83$, and $2.33 \mathrm{~m}$ at the lower layers, respectively. The difference between the two layers was significant. The differences of the ranges indicated that the ecological factors influenced SWC at different spatial scales. The ranges of SWC at the top layer were smaller than that at the lower layer for the four sampling times, which indicated that SWC at the top layer was less spatially dependent, and SWC at the top layer was influenced greatly by ground ecological factors such as litters and soil crust. The 42 $\mathrm{mm}$ rainfall was very heavy in Horqin Sandy Land, and it can easily infiltrate to $40 \mathrm{~cm}$ underground layer. Soil water was accumulated at the lower layer, which decreased the spatial variance to some extend. Moreover, the roots of grasses in sandy land were mostly distributed at the depth of 0-20 cm (Zhou, 2008; Cheng et al., 2009). Therefore, the evaporation of soil and transpiration of plants resulted in the greater spatial variance of SWC at the $0-20 \mathrm{~cm}$ layer, in addition to the difference of soil heterogeneous and micro-topography.

Range of soil water content was analyzed in sandy grassland, semi-mobile dune and inter-dune bottom land after a $27 \mathrm{~mm}$ rainfall in Horqin Sandy Land, and the fluctuated ranges of SWC were from $9.72 \mathrm{~m}$ to $180.80 \mathrm{~m}$ at $0-20 \mathrm{~cm}$ layer, and from $4.55 \mathrm{~m}$ to 18.02 $\mathrm{m}$ at 20-40 $\mathrm{cm}$ layer (Zhao et al., 2006), which was much higher than that obtained in our research, but similar result was observed (Zuo et al., 2005), which ranged from $2.26 \mathrm{~m}$ to $6.63 \mathrm{~m}$, with a higher value at the lower layer than that at the top layer.

\section{Conclusions}

(1) SWC under C. microphylla shrub decreased at both top and lower layers after the $42 \mathrm{~mm}$ rainfall as time going on, and SWC at the lower layer was higher than that at the top layer for all the four sampling times. At the top layer, SWC outside the shrub canopy was higher than that inside within 5 days and became the same inside and outside the shrub canopy on the 10th day. SWC inside the shrub canopy turned higher than that outside on the 15th day. At the lower layer, SWC outside the shrub canopy was higher than that inside all the time, but the difference was getting smaller as time going on.

(2) SWC fitted the theoretical variogram model perfectly at both layers on the 1st, 5th, 10th and 15th day after the rain. The spatial autocorrelation of SWC was strong except the top layer on the 15th day. The effective range at the top layer was higher than that the lower layer, and their difference was significant. SWC at the top layer was less spatially dependent than that at the lower layer.

C. microphylla shrub in the research developed an efficient way to redistribute rain water and has a good 
water-use. So it is one of the most important shrubs in Horqin Sandy Land for resisting desertification, and it should be widely planted to control the degradation on sandy land.

\section{Acknowledgements}

This paper was financially supported by the National Basic

\section{References}

Alamusa, Jiang D M, Fan S X, et al. Soil moisture dynamics under artificial Caragana microphylla shrub. Chinese Journal of Applied Ecology, 2002, 13(12): 1537-1540.

Alamusa, Jiang D M, Pei T F. Soil moisture infiltration dynamics in plantation of Caragana microphylla in Horqin Sandy Land. Chinese Journal of Ecology, 2004, 23(1): 56-59.

Chen F S, Zeng D H, Chen G S, et al. Comparative analysis of spatial patterns of soil moisture under different land use types in Kerqin Sandy Land. Chinese Journal of Ecology, 2003, 22(6): 43-48.

Cheng W J, Cui J Y, Min F H, et al. Root distribution characteristics of three turf grasses and their impact on soil nutrient content. Acta Prataculurae Sinica, 2009, 18(1): 179-183.

He Z B, Zhao W Z. Characteristics of soil moisture of different vegetation types in initial stage of fixed sand dune of semi-arid region. Journal of Soil and Water Conservation, 2003, 17(4): 164-167.

Hu X, Liu L Y, Yan P. The effect of different soil surface on soil moisture in the farming-pastoral ecotone zone - a study case of Taipusi Banner, Inner Mongolia. Research of Soil and Water Conservation, 2006, 13(2): 105-107.

Huang G, Zhao X Y, Su Y G, et al. Assessment on the effects of Pinus sylvestris var. mongolica plantation on microenvironment improvement in the Horqin Sandy Land. Arid Zone Research, 2008, 25(2): 212-218

Isaaks E, Srivastava R. Applied Geostatistics. New York: Oxford University Press, 1989. 561

Jia Y P, Su Z Z, Duan J N. Spatial variability of soil organic carbon at small watershed in Gully Region of Loess Plateau. Journal of Soil and Water Conservation, 2004, 18(1): 31-34.

Kang H Z, Zhu J J, Xu M L. Study on water physiological properties of the artificially-planned sapling of Pinus sylvestris var. mongolica in Horqin Sand Land. Arid Zone Research, 2007, 24(1): 15-22.

Liu Y B, Chen H S, Gao Q Z. A new view of sandy land soil moisture dynamics research. Journal of Desert Research, 1997, 17 (1): 95-98.

Sharma K D. Water resources: an overview of world deserts. Annual Arid Zone, 1991, 30(4): 283-300.

Shi X H, Li C Y, Liu T X. Analysis about soil humidity characteristics of different plants areas in Horqin Sandy Land. Journal of Yunnan Agricultural University, 2006, 12(3): 355-359.

$\mathrm{Su}$ Y Z, Li Y L, Zhao H L. Soil properties and their spatial pattern in a degraded sandy grassland under post-grazing restoration, Inner
Research Program of China (973 Program) (2009CB421303), the National Natural Science Foundation of China (40801036) from the Cold and Arid Regions of Environmental and Engineering Research Institute, Chinese Academy of Sciences. Our thanks should go to all the members of Naiman Desertification Research Station, Chinese Academy of Sciences, for their help in field and laboratory work, and the anonymous reviewers for their appropriate comments and English correcting.

Mongolia, northern China. Biogeochemistry, 2006, 79: 297-314.

Wang Z, Wang L, Liu L Y, et al. Preliminary study on soil moisture in dried layer of sand dunes in the Mu Us Sand Land. Arid Zone Research, 2006, 23(1): 89-92.

Zhao H L, Cui J Y, Zhou R L, et al. Soil properties, crop productivity and irrigation effects on five croplands of Inner Mongolia. Soil \& Tillage Research, 2007, 93: 346-355.

Zhao H L, Zhao X Y, Zhang T H, et al. Desertification processes of sandy rangeland due to over-grazing in semi-arid area, Inner Mongolia, China. Journal of Arid Environments, 2005, 62: 309-319.

Zhao W, Zhang T H, Liu X P, et al. Spatiotemporal variation of soil moisture and its relations with Artemisia halodendron root water content as affected by rainfall. Chinese Journal of Ecology, 2008, 27(2): 151-156.

Zhao W Z, Liu Z M, Chang X L. A study on the soil moisture status under the vegetations in Naiman sand area. Arid Zone Research, 1992, 9(3): 40-44.

Zhao W Z. Impact of plantation on spatial heterogeneity of soil moisture in Horqin Sandy Land. Acta Pedologica Sinica, 2002, 39(1): 113-119.

Zhao X Y, Zuo X A, Zhao H L, et al. Spatial variability of soil moisture after rainfall in different type sands of Horqin Sand Land. Arid Land Geography, 2006, 29(2): 275-281.

Zhou M H. The Study on Distribution Characteristics of the Natural Grassland Vegetation Roots in Yunwu Mountain in Ningxia. Master's dissertation. Yangling: Northwest Agriculture and Forest University, 2008. 22-28.

Zhu Z D, Chen G T. The Sandy Desertification in China. Beijing: Science Press, 1994. 7-268.

Zuo X A, Zhao H L, Zhao X Y, et al. Spatial pattern and heterogeneity of soil properties in sand dunes under grazing and restoration in Horqin Sandy Land, Northern China. Soil \& Tillage Research, 2008, 99: 202-212.

Zuo X A, Zhao X Y, Zhao H L, et al. Spatial variability of soil moisture responding to drought and rainfall in sandy grass land of Horqin. Journal of Soil and Water Conservation, 2005, 19(1): 140-144.

Zuo X A, Zhao X Y, Zhao H L, et al. Spatial pattern and heterogeneity of soil organic carbon and nitrogen in sand dunes related to vegetation change and geomorphic position in Horqin Sandy Land, Northern China. Environmental Monitoring and Assessment, 2010, 164, doi: 10.1007/s10661-009-0872-2. 